\title{
PLANNING FOR SUSTAINABILITY IN THE AUSTRALIAN PULP AND PAPER INDUSTRY
}

\author{
WILLIAM J. HURDITCH \\ The Fifth Estate, Australia
}

\begin{abstract}
Securing domestic production of pulp and paper is important for Australia due to the country's relative economic isolation and its historical reliance on imports of paper and other forest products. However, Australia has had a chequered history of dispute and investment risk surrounding major pulp and paper developments. A brief history of this industry sector's development reveals a complex interplay between science, community sentiment, ideology, politics and regional development imperatives. A lack of suitable sustainable planning instruments and approaches has hindered advancement towards the balanced, modern development of the industry. In New South Wales, the State planning law was one of the first, globally, to embrace and explicitly include attention to the principles of ecologically sustainable development for all project assessments. It has enabled, with its suitably-applied regulatory apparatus, the successful approval and environmental permitting of a number of major industrial projects which have embodied many of the attributes of modern circular manufacturing. A case study of such a successful major investment in the pulp and paper sector is presented. The study highlights the central importance of up-front sustainability commitments by project proponents in their engagement with the community through the statutory planning system. In concert with timely and efficient performance monitoring and reporting disciplines, a high degree of investment certainty for such ambitious projects has been possible. It is concluded that, as well as good science and transparent assessment processes, success in major industrial projects required the adoption of a culture of continuous innovation and process improvement, throughout the life of the project, to realise genuinely sustainable development.
\end{abstract}

Keywords: Australia, planning law, pulp and paper, circular manufacturing.

\section{INTRODUCTION}

Approaches to statutory planning for major and often complex industrial projects have evolved over the past 50 years along a continuum of fashions. These have ranged from, in earlier years, a laissez faire attitude by regulators, especially in relation to environmental permits and community concerns, through to a more reactive and severe form of regulatory command and control. Neither has delivered sustainable outcomes, for different reasons [1].

More recently, some jurisdictions have adopted more flexible and collaborative approaches. These, though still environmentally rigorous, take account of the oftencompeting needs (or perceptions) of governments to provide robust approval terms, on the one hand, and of developers to secure planning certainty for their large investment commitments, on the other.

For development to be sustainable, new approaches to planning are required that promote shared values between investors and regulators. Anticipating this at the turn of the new millennium, one commentator observed an emerging culture whereby governments deploy their democratic power more subtly, toward the goal of genuinely sustainable prosperity:

...Command is slowly giving way to persuasion and negotiation... The new role for government is that of facilitator. Governments now must negotiate rather than mandate change. Power must be used more subtly if it is to be sustained. Government is more about intermediating between different interests and less about imposing majority will on an unwilling minority... Governments must stimulate 
innovation and create an appropriate framework within which our companies can prosper [2].

This paper describes the successful application of planning law in the Australian regional (State) jurisdiction of New South Wales, in relation to a major development project within an important industry sector with a difficult track record of development and a recent history of fraught approval processes.

\section{IMPORTANCE OF DOMESTIC PRODUCTION OF PAPER}

\subsection{Historical context}

Since its settlement by Europeans in the late 1700s Australia has relied on the importation of paper from overseas to satisfy the majority of its domestic needs.

Initially, this was because local industries had not had the chance to develop to supply the growing colony of New South Wales. However, by the 1840s, while wood fibre was progressively taking over from recycled fabrics ("rags") for papermaking feedstock in Europe and the Americas, Australia's transition was challenged by the unfamiliar properties of its native wood species which were proving difficult to process. In particular, Australia's dominant Eucalypts species, being hardwoods, contained short fibres and also variable amounts of tannins and other contaminants unfamiliar to papermaking scientists of the day.

Ironically, the first reported pulping of Eucalyptus species for papermaking took place in Portugal in 1909, using Australian-sourced trees [3]. Thirteen more years would elapse before the first successful commercial trials occurred in Australia. Accordingly, Australia's rapidlygrowing population continued to consume more paper than could be produced onshore, despite the substantial efforts of Australian Government scientists and publishers to achieve self-sufficiency in these important commodity products.

The historical facts outlined above have given rise to an embedded market "culture" in which importing paper is seen as the norm. As a result, notwithstanding Australia's relatively small population of less than 25 million people and its very large land base with sizable per capita forestry resource, the country continues to import more than 40 per cent of its paper needs (Table 1). This carries an annual cost in foreign exchange of around $\$ 3$ billion [4].

The upswing in paper exports between 1996 and 2006 was attributable to a single, discrete development in bulk packaging grade paper manufacturing specifically targeted at the export market, evidenced by the fact that the absolute volume of paper imports for domestic use continued to rise during this period.

At the same time, Australia was, and remains, one of the world's largest exporters of woodchips for papermaking, with countries like Japan and Korea being major importers of Australian pulpwood.

Table 1: Australia's continuing reliance on paper imports ('000 tpa). (Source: Australian Government data.)

\begin{tabular}{lrrc}
\hline & $\mathbf{1 9 9 6}$ & $\mathbf{2 0 0 6}$ & $\mathbf{2 0 1 6}$ \\
\hline Consumption & 3,431 & 4,139 & 3,689 \\
Production & 2,320 & 3,207 & 3,224 \\
Exports & 217 & 811 & 1,130 \\
\hline Imports & $\mathbf{1 , 1 1 1}$ & $\mathbf{1 , 7 9 6}$ & $\mathbf{1 , 5 9 4}$ \\
\hline
\end{tabular}


The irony of this situation, which has persisted since the early 1970s, has not been lost on policymakers and governments who have variously observed the misalignment of Australia's forest products trade situation, for example:

Australia's lack of manufacturing capacity has seen us exporting relatively low value unprocessed wood while importing high value processed paper products. It is expected Australia's trade deficit will continue to increase unless there is substantial new investment in pulp and paper manufacturing capacity. Over recent years, uncertainty about access to forest resources and the high environmental standards expected in pulp mills have discouraged investment in value-adding operations such as pulp mills [5].

\subsection{Growing conflict in developing domestic pulp and paper facilities}

The early 1970s saw the start of a significant, highly vocal backlash against harvesting Australia's native forests for commercial timber production, and particularly for pulpwood (typically termed "woodchips"). The history of the so-called "forest wars" has been chronicled and analysed in depth by many commentators, for example [6], [7].

Table 2: History of major pulp/paper mill development proposals in Australia.

\begin{tabular}{|c|c|c|}
\hline Year & Project & Status \\
\hline 1937 & $\begin{array}{lcr}\text { APPM } & \text { paper } & \text { mill } \\
\text { constructed } & \text { in } & \text { Burnie, } \\
\text { Tasmania. } & & \end{array}$ & Demolished in 2010 \\
\hline 1937 & $\begin{array}{l}\text { APM paper mill commences } \\
\text { in Maryvale, Victoria }\end{array}$ & Continues to operate \\
\hline 1941 & $\begin{array}{l}\text { HWT newsprint mill built in } \\
\text { Boyer, Tasmania }\end{array}$ & Continues to operate \\
\hline 1957 & $\begin{array}{l}\text { Shoalhaven Paper mill } \\
\text { opened in Bomaderry, NSW }\end{array}$ & Closed in 2015 \\
\hline 1981 & $\begin{array}{l}\text { ANM newsprint mill opens } \\
\text { in Albury, NSW. }\end{array}$ & Continues to operate \\
\hline 1989 & $\begin{array}{l}\text { Proposed Wesley Vale pulp } \\
\text { mill, Tasmania }\end{array}$ & $\begin{array}{l}\text { Blocked by Commonwealth } \\
\text { Government decision }\end{array}$ \\
\hline 1993 & $\begin{array}{l}\text { Kimberly Clark opens its } \\
\text { tissue pulp mill at } \\
\text { Tantanoola, South Australia }\end{array}$ & Closed and demolished in 2011 \\
\hline 2000 & $\begin{array}{l}\text { Visy opens its Kraft pulp and } \\
\text { paper mill at Tumut NSW }\end{array}$ & Continues to operate \\
\hline 2006 & $\begin{array}{l}\text { Proposed Heywood pulp } \\
\text { mill, Heywood, Victoria }\end{array}$ & $\begin{array}{l}\text { Did not proceed due to failure to } \\
\text { secure finance }\end{array}$ \\
\hline 2007 & $\begin{array}{l}\text { Proposed Protavia pulp mill, } \\
\text { Penola, South Australia }\end{array}$ & $\begin{array}{l}\text { Did not proceed due to failure to } \\
\text { secure finance }\end{array}$ \\
\hline 2011 & $\begin{array}{l}\text { Proposed Gunns pulp mill, } \\
\text { Bell Bay, Tasmania }\end{array}$ & $\begin{array}{l}\text { Did not proceed due to failure to } \\
\text { secure finance and full approval }\end{array}$ \\
\hline
\end{tabular}


For our present purposes, however, it is sufficient to list some of the cases and factors that have featured in the ongoing controversy, to assist in understanding the central role of sustainable planning in delivering better overall outcomes in relation to complex paper manufacturing facilities.

Table 2 summarises the history of wood fibre-based pulp and/or paper mill proposals and developments $\mathrm{s}$ in Australia. The list reveals that, of the total of 11 projects, 4 were abandoned before they could commence production, and a further 3 facilities have been closed and/or demolished. Only 4 mills continue to operate today.

The period from the late 1980s onwards has seen particular instability and controversy, with only two mills becoming operational out of the six projects proposed in those years. Four of the failed projects were either blocked by government intervention and/or could not secure appropriate finance.

Australia urgently needed some examples of development projects that could serve as exemplars of good planning practice and that would deliver robust outcomes for their communities and their investors alike.

\section{PLANNING FOR SUSTAINABILITY IN MAJOR RESOURCE PROJECTS}

The historical circumstances described in the previous section are not uncommon from histories of industry development in other jurisdictions around the world.

The causes and outcomes are typically complex and derive from the largely unpredictable interplay between a suite of drivers, including historical, economic, political, technical and societal ones. While retrospective judgements can sometimes be over-simplistic, it is clear that a common source of dispute and unstable development outcomes is a failure to adopt an integrated and robust environmental planning and assessment process and approval as a basis for sustainable development and investment certainty [8].

The remainder of this paper examines a case study of a successful pulp and paper mill development in the Australian State of New South Wales, focussing on the application of modern planning law unique to that jurisdiction.

\subsection{Brief history of environmental planning in New South Wales}

Up until the late 1970s New South Wales' urban and related development planning activity was authorised by various customary or existing usage rights and by the Local Government Act 1919 which had been amended at the end of World War II by the Local Government (Town and Country Planning) Amendment Act 1945 No 21 to provide for town and country planning schemes to be developed [9]. Plans and schemes tended to be quite localised, without deep consideration as to the larger needs of balanced development of the State. The continuing emphasis on "town and country", in name and sentiment, is instructive of the age, common with most other countries and jurisdictions, in which the built environment took priority over the natural environment. Not only that, but the legitimate concerns of citizens having no direct commercial interest in a planning approval were typically disregarded. In sum:

“...The environment rated barely a mention, and a private citizen who sought to enforce the law had, generally, no standing and had to apply for the AttorneyGeneral's fiat. Public authorities were largely uncontrolled...." [10].

In 1963 the State Planning Authority was established to give wider ambit to planning controls and initiatives, but still within a largely "built environment" mindset. 
Things changed markedly in 1979 when, after almost a decade of intense reform discussion, the then Parliament of New South Wales passed a radically new package of legislation entitled the Environmental Planning and Assessment Act 1979 (EP\&A Act).

Enactment of the EP\&A Act was widely seen as a landmark step toward the proper integration of development planning explicitly aimed at integrating the hitherto competing demands of economic, social and biophysical spheres of interest. This innovation has been lauded as "... in many respects a most significant event in Australian environmental and planning law..." [11].

The then NSW Minister for Planning and Environment, the Hon. Paul Landa, signalled the key intent of the legislation as being, inter alia, to (1) broaden the scope of planning to effectively embrace economic, social and ecological considerations in the preparation of environmental plans and in development control, (2) speed up decision-making, and (3) foster investment and facilitate growth [12].

Notably for the present discussion, although not included in word until 1997 (under an amendment to the definitions), the intent of the EP\&A Act, and the court's interpretation of that intent, embraced the vision of achieving ecologically sustainable development (ESD) through good planning procedures and decisions. This mandated active consideration of the four principles of ESD in all assessments of planning proposals, namely (1) the operation of the precautionary principle, (2) regard for inter-generational equity, (3) attention to the need for conservation of biological diversity and ecological integrity, and (4) introduction of improved valuation, pricing and incentive mechanisms for maintaining the provision of environmental goods and services [13].

\subsection{Features of the NSW Environmental Planning \& Assessment Act}

In addition to its overt recognition of the principles of ESD, there are some particular features of the EP\&A Act that have helped contribute to robust sustainable development outcomes. They include:

- An enlightened definition, and comprehensive interpretation, of "environment" for the purposes of planning, which recognises that "environment" embraces social, economic and biophysical aspects of the surroundings of people

- A nested planning framework that recognises the legitimate respective stakes of actors at the tiers of State, region and local community

- Clear development assessment rules, guidelines and processes

- Legislated maximum approval response times and associated process disciplines

- Mandated consultation with affected and otherwise interested third parties, including adoption of formal consultation plans

- Integrated approval of the suite of consents, permits and licences typically required for complex developments

- Wide legal standing of people to challenge procedural failures

- Suitably expert, technically-focused assessors and panels for significant development proposals

- A robust dispute resolution mechanism through a specialist Court, operating independently of government

The EP\&A Act remains the primary legislative and regulatory gatekeeper for development approval and control in New South Wales. Despite significant changes made to the Act by the NSW Parliament in 2017, mainly to contemporise and streamline its functions 
[14], the essential vision and purpose remains. And, while this law and its application certainly has room for further evolution and improvement, and critics remain, it continues to provide a needed degree of stability and investment certainty, with environmental rigour, for development of major projects within the State.

\section{CASE STUDY - SUSTAINABLE PULP AND PAPER MILL DEVELOPMENT}

Securing sustainable planning outcomes for major projects is a two-way street. On the regulator's side, it requires a commitment to provide a predictable, time-disciplined, sciencebased approval pathway and procedures. On the developer's side, it requires a commitment to a process of genuine consultation with materially-interested parties, best available project design and technology, and a business culture focused on operational excellence and continuous improvement.

The following sections present a case study of what has been widely considered an exemplar of sustainable planning for a major resource-based industrial project.

\subsection{Background and project rationale}

In the mid-1990s an Australian manufacturing company proposed to develop a major new pulp and paper facility within a regional area of the State of New South Wales.

The company, Visy Industries, had not at that time operated such a complex plant, so technical and market risks were considered significant. Further, the idea came with approval and permitting risks given the history of controversy surrounding similar development proposals in Tasmania, Victoria and South Australia, detailed earlier in this paper. Accordingly, the company determined it would need to make an early commitment to advancing the project according to sustainable planning principles. These included wide consultation, adoption of world-best design and technology, operational excellence and continuous improvement. This required the allocation of significant financial and personnel resources over and above what might typically be expected of such project.

As detailed below, these principles played out in the development process as the project advanced from concept to reality, over a period of some six years.

\subsection{Project overview}

Visy's pulp and paper mill is located near the rural town of Tumut in the Eastern Riverina region of New South Wales. This region has extensive stands of pine plantations, of mainly Pinus radiata species, established during the 1960 s to 1980 s as part of a governmentsupported plantation-based regional development initiative.

Visy, one of Australia's foremost materials recycling and remanufacturing companies, identified a market need to produce wood-based, industrial grade paper to supplement the significant volumes of recycled paper it was already producing in the three largest Australian cities: Sydney, Melbourne and Brisbane.

Manufacturing paper from waste paper feedstock is now commonplace around the world. However, especially in small domestic markets like Australia's, continuous recovery and recycling of paper can lead to progressive fibre degradation of the national recyclate stock. The injection of a source of virgin fibres from a plantation pine-based mill was seen as a solution.

The chosen underlying technology for the mill was the Kraft process, which involves a closed-loop chemicals and energy cycle by exploiting two inherent constituents of timber, lignin and cellulose [15]. Although first used commercially in the $1880 \mathrm{~s}$, the industrial and 
environmental elegance of the Kraft process has recently come into fresh focus as a model of "circular manufacturing" [16]. Its most important features are the tight cycling and recycling of materials, water and energy throughout the process, thus avoiding waste, minimising use of external energy and maximising product value.

In the case of the Tumut initiative, the Company made a number of public, advance commitments regarding the project's design and configuration. These included no chlorine bleaching of pulp at the site, maximum water reuse, no offsite odour or effluent from the mill, and the use of only plantation-grown timber as wood-based feedstock. These commitments were seen as major markers of modern, environmentally responsible manufacturing [17]. As a result, the project has received a number of awards for environmental and design excellence and continues to innovate by adopting latest technology as it becomes available.

The mill development was originally designed to produce up to 450,000 tonnes per annum of unbleached Kraft paper, on two paper machines, for sale in domestic and export markets.

\subsection{The chosen planning pathway}

Depending on the nature of a proposed development, the granting of planning approval for development projects under the EP\&A Act may occur at either a State level by the State Planning Minister or an independent planning commission, or at a local level. A recent innovation for local level approvals is to replace the previous planning consent role of the elected Councillors for the area within which the development is proposed (or their delegate), by a senior Council officer or by a Local Planning Panel or Regional Planning Panel, constituted by experts.

The EP\&A Act provides proponents of development certain appeal rights, as it does for opponents, in some instances. Where there is an appeal, a specialist court, the Land and Environment Court, becomes the consent authority. The court also has jurisdiction to declare approvals invalid if there is found to be a failure to comply with legal requirements in the processing and determination of development proposals.

Developments that are identified as being of State significance, or which otherwise exceed prescribed thresholds as to activity and/or likely impacts (termed "designated development"), require detailed environmental impact assessment and mandated public consultation.

Because of its size, complexity and projected capital requirement for the Tumut pulp and paper mill, it was deemed of State significance, and the adopted planning pathway was for the then State Minister for Planning to be the consent authority. Under this pathway, the scope of the required environmental impact assessment, including technical standards and protocols, are prescribed by the Department of Planning. The Department, in turn, seeks and synthesises additional prescriptions from other relevant permitting bodies, such as the Environment Protection Authority. In this way, all of the relevant legislative approval requirements are contemplated and communicated to the developer, in advance.

In February 1998 the application for planning approval was lodged with the Department of Planning, together with a detailed environmental impact assessment report. The application was for a "staged development", anticipating a two-stage development horizon, starting with the first paper machine at 300,000 tonnes per annum output. A second development stage, adding 150,000 tonnes per annum output on a second paper machine, was contemplated for investment within the medium-term future.

In addition to the routine inter-departmental review of the assessment, the Minister appointed an independent, technically-competent Commission of Inquiry to consider the proposal and make recommendations to the Minister as to the overall merit of the proposal, and regarding any special approval and/or permitting conditions. This inquiry process, 
uniquely affording access by members of the public, government representatives, NGOs, and other interested stakeholders, provided a non-adversarial forum to test the developer's assessment and request changes.

The Commission of Inquiry presented its report to the Minister in June 1998 [18], and the Minister granted his conditional approval for the staged development in November of the same year.

In parallel with the evolution of the EP\&A Act, there were a number of other legislative reforms being contemplated for sustainable natural resources management in New South Wales. These included the regulation of timber plantation developments under the proposed Timber Plantations (Harvest Guarantee) Amendment Bill 1997, and provisions for the State to enter into long-term timber supply agreements, needed to underpin very large private investment commitments for processing infrastructure. To give early effect to these reforms within the required investment decision-making time for the mill project, the State Parliament approved the passage of special-purpose project facilitation legislation [19]. Importantly, however, this legislation did not override or otherwise subjugate the provisions or disciplines of the EP\&A Act with respect to this project.

As well as following the mandatory planning pathway and processes, the Company engaged deeply and openly with the local Council throughout the planning phase, even though the Council was not the planning consent authority. The rationale was to seek Council's and the community's input on various aspects of the project that could potentially impact on community infrastructure and social dynamics. Matters canvassed included water and gas supply infrastructure, bushfire management support by the Company, local traffic management, accessing local labour and services for the mill construction and operations, and farmland management customs and expectations. To give effect to some of these matters, the Company negotiated a voluntary memorandum of understanding with the local Council, as a representative of the community's interests, needs and wishes.

\subsection{Further staged development}

Following construction, commissioning and the first five years of successful operation of stage one of the development, the Company decided to proceed with investing in a second paper machine. The bespoke mill layout had been configured to enable the second line to be "slotted in" to the existing footprint, minimising aesthetic and other impacts and demonstrating best-practice design.

However, it was also decided that the second stage would aim to produce a further 400,000 tonnes per annum of paper output, rather than the originally-envisaged 150,000 tonnes per annum. Accordingly, because of the additional size and scope compared with the original stage development approval, it was determined that a fresh environmental assessment would be required.

The Company proceeded to undertake the required impact assessment work to secure a further planning approval. The second stage of the mill was approved, with revised consent conditions, during 2009.

Further process enhancements and technology upgrades have been undertaken since that time and continue to this day, as part of the continuous improvement and sustainable growth of this facility.

\section{FACTORS CONTRIBUTING TO SUSTAINABLE PLANNING OUTCOMES}

There are typically many factors that can contribute to the success or the failure of a major, complex development project. In the case of the Tumut pulp and paper mill, given the prior 
turbulent 20-year history of this particular industrial sector, we can identify seven factors that set this project apart from others in terms of its sustainable planning success. These success factors are summarised in Table 3, together with some practical implications for similar development projects.

Table 3: Factors contributing to sustainable planning - Tumut case study.

\section{PLANNING FACTOR \\ 1. A COMMITMENT TO SUSTAINABLE BUSINESS PRACTICES}

\section{A BALANCED STATUTORY ENVIRONMENTAL PLANNING SYSTEM}

\section{DEEP STAKEHOLDER ENGAGEMENT AND LOCAL COMMUNITY CONSULTATION}

\section{ENVIRONMENTALLY-AWARE PROJECT DESIGN}

\section{STAGED PROJECT DEVELOPMENT}

6. BEST AVAILABLE TECHNOLOGY

\section{CONTINUOUS IMPROVEMENT}

\section{PRACTICAL IMPLICATION}

A corporate commitment to sustainable business practices ensures that the principles of circular manufacturing will give rise to genuinely environmentallysensitive project development and enterprise management Attracting and maintaining economicallyviable, wealth-creating business development requires a modern, wellresourced state environmental planning system, with supportive legislation and procedures and predictable response disciplines

Engaging early, genuinely and continuously with affected stakeholders and opinion-formers, especially immediate neighbours and NGOs, builds trust and can introduce project changes that will foster ongoing community acceptance.

The purposeful, up-front design of technically-advanced plant processes, such as closed-loop materials, energy and water systems, will ensure ongoing sustainable business operations Adopting a staged development approach, with a progressive roll-out of the project, in line with commercial realities and community expectations, can leave room for design and process changes in each successive stage Selection and incorporation of best available technology will ensure an efficient operational environment is maintained, keeping abreast of changing community expectations A supportive corporate culture that promotes and embraces innovation and continuous improvement in technology and operational excellence will pre-empt external changes and capitalise on disruptive forces 
The seven sustainable planning factors outlined above have played, and continue to play, a key role in delimiting the way the project impacts the environment - social, economic and biophysical. Importantly, though, they can also be shown to have contributed positively to a more robust and sustainable business outcome. For example, greater attention to internal water recycling has lessened drought impact risks and maximising the generation of bioenergy and implementation of energy-efficiency investments has reduced the business's reliance on increasingly-costly grid-supplied electricity and gas.

Socially, fostering greater long-term community trust through continuous engagement and consultation has provided a firmer platform for further development proposals and plant enhancements, as and when they are required.

\section{CONCLUSIONS}

The case study of a successful sustainable planning outcome presented here could provide a model, or at least some helpful features of a system, that may be usefully applied elsewhere. These include a corporate commitment to sustainable business practices, deep and ongoing stakeholder engagement and consultation, environmentally-aware project design and an attitude of continuous improvement and innovation within the enterprise.

While all jurisdictions have their unique histories and circumstances, there are common elements of major industrial planning that, when observed, can lessen investment risk on the side of the developer, and heighten environmental integrity on the side of communities and regulators.

All planning arrangements, like all human systems, are works in progress and need to evolve and improve as community standards and economic circumstances change.

The case study presented in this paper demonstrates that, in the case of planning for major developments in New South Wales, the EP\&A Act's design and provisions has offered a coherent, integrated and responsible legislative and procedural framework for promoting sustainable planning in the increasingly complex world of business. As such, its approach may have features worth consideration by other jurisdictions faced with similar sustainable development challenges.

\section{REFERENCES}

[1] Holley, C. \& Shearing, C., Policing and new environmental governance. The Sage Handbook of Global Policing, eds B. Bradford, B. Jauregui, I. Loader \& J. Steinberg, Sage, 2016.

[2] Tanner, L., Open Australia, Pluto Press: Annandale, p. 13, 1999.

[3] Algar, W.H., Forestry and forest products. Chapter 4 in Technology in Australia 17881988. Online. www.austehc.unimelb.edu.au/tia/. Accessed on: 23 Apr. 2018. Compiled by the Australian Academy of Technological Sciences and Engineering. Melbourne, Australia, 1988.

[4] Australian Bureau of Statistics, Catalogue 5368.0 International Trade in Goods and Services, Canberra, 2018.

[5] Commonwealth Department of Agriculture, Fisheries and Forestry-Australia, Submission to the House of Representatives Standing Committee on Industry, Science and Resources' Inquiry: Increasing Value-Adding to Australia's Raw Materials, Canberra, 1999.

[6] Ajani, J., The Forest Wars, Melbourne University Press, 2007.

[7] Poynton, S.A. \& Hurditch, W.J., Cooperation and conflict in forest management: Applying a theoretical model to the Australian problem. Australian Forestry, 58(2), pp. 58-64, 1995. DOI: 10.1080/00049158.1995.10674645. 
[8] Routley, R. \& Routley, V., The Fight for the Forests, 3rd ed., Research School of Social Sciences, ANU: Canberra, 1975.

[9] Howes, M. et al., Environmental sustainability: a case of policy implementation failure? Sustainability 9, p. 165, 2017. DOI: 10.3390/su9020165.

[10] Whitehouse, J. \& Harmsworth, F., (eds), Development and Planning Law in New South Wales, CCH: Australia, 2012.

[11] Slattery, M., quoted in: Swearing-Out Ceremony of the Honourable Justice Neal Bignold as a Judge of the Land and Environment Court of New South Wales, The Land and Environment Court of New South Wales, 13 Mar., p. 12, 2007.

[12] Barker, M., How planning and environmental law has shaped our cities. Presented at 2007 Planning Institute of Australia National Congress, 1-4 May, Perth, p. 19, 2007.

[13] Parliament of New South Wales, 21 November 1979, Legislative Council Hansard, p. 3346 and pp. 3351-3353, 1979.

[14] Edwards, T., Sustainable development. NSW Parliamentary Library Research Service briefing paper No. 4/09, Sydney, Australia, 2009.

[15] NSW Legislative Council of the Parliament of New South Wales, Environmental Planning and Assessment Amendment Bill 2017, Second Reading. Hansard 18 Oct., pp. 70-73, 2017.

[16] Young, R.A., Kundrot, R. \& Tillman, D.A., Pulp and paper. Encyclopedia of Physical Science and Technology, ed. R.A. Meyers, 3rd ed., Academic Press: New York, pp. 249-256, 2003.

[17] Ellen Macarthur Foundation, 3-Towards the Circular Economy-Accelerating the Scale-Up Across Global Supply Chains, Ellen Macarthur Foundation and The World Economic Forum, 2014.

[18] Puhr, R. (ed.), Zeroing in on waste brings Visy big returns. Spectrum No. 24-2, Andritz Corporation, 2011.

[19] Cleland, K., Proposed Kraft Pulp and Paper Mill Project Tumut, Visy Paper Pty Limited, Report of the NSW Commissioners of Inquiry for Environment and Planning. Jun. 1998.

[20] Parliament of New South Wales, Visy Mill Facilitation Act 1997 No 139, Sydney, NSW, 1997. 